\title{
PENGARUH PENAMBAHAN SEMEN PORTLAND, ABU SEKAM, DAN FLY ASH TERHADAP NILAI DAYA DUKUNG TANAH LEMPUNG SEBAGAI SUBGRADE PERKERASAN JALAN
}

\author{
Nuah Kalawa ${ }^{1}$, Fatma Sarie ${ }^{2}$ dan Mohammad Ikhwan Yani ${ }^{3}$ \\ ${ }^{123}$ Program Studi Teknik Sipil, Fakultas Teknik, Universitas Palangka Raya, \\ E-mail: nuahkalawa61@ gmail.com ${ }^{1}$, fatmasarie@jts.upr.ac.id ${ }^{2}$, dan \\ m.ikhwanyani@eng.upr.ac.id ${ }^{3} /$ HP.+6285332924082 1
}

\begin{abstract}
ABSTRAK
Berdasarkan observasi lapangan di Kelurahan Tumbang Rungan Palangka Raya, Kalimantan Tengah kondisi tanah di sekitar lokasi tersebut didominasi oleh tanah lempung. Tanah lempung berpengaruh pada konstruksi bangunan dan jalan, yaitu dapat mengalami kendala dalam pembangunannya. Penelitian ini bertujuan untuk menstabilisasi tanah asli menggunakan bahan aditif seperti semen, abu sekam, dan fly ash. Hasil pengujian sifat fisik tanah asli diperoleh nilai, kadar air $(w)=41,37 \%$; berat isi kering $\left(\gamma_{\mathrm{d}}\right)=1,45 \mathrm{~g} / \mathrm{cm}^{3}$; berat jenis $(G s)=2,70 ; \mathrm{LL}=46,49 \%$; PL $=$ $30,33 \%$; PI $=16,16 \%$; SL $=22,97 \%$. Menurut AAHSTO tanah tersebut diklasifikasikan sebagai tanah berlempung dalam kelompok A-7-5. Hasil pengujian sifat mekanik tanah asli menunjukan bahwa nilai kadar air optimum $(O M C)=$ $26,30 \%$; berat isi kering $\left(\gamma_{\mathrm{d} \max }\right)=1,420 \mathrm{~g} / \mathrm{cm}^{3}$; dan nilai CBR tanah asli adalah 3,97\%. Campuran semen, abu sekam, dan fly ash berdampak pada meningkatnya nilai CBR. Penambahan variasi campuran 5\%, 7,5\%, dan $10 \%$ menghasilkan nilai CBR rencana yang meningkat sebesar $6,80 \%$; 8,00\%; dan 8,80\%. Nilai CBR terbesar terjadi dipenambahan fly ash $10 \%$ yaitu sebesar $8,80 \%$ meningkat $121,66 \%$ dari nilai CBR tanah asli. Dari hasil nilai CBR rencana yang didapat, nilai DDT meningkat sebesar 5,28, 5,58, dan 5,76. Nilai DDT terbesar terjadi dipenambahan fly ash 10\% yaitu sebesar 5,76 meningkat 30,37\% dari nilai DDT tanah asli.
\end{abstract}

Kata kunci: CBR, Abu Terbang, Semen, Abu Sekam, Tanah Lempung

\section{ABSTRACT}

Based on field observations in Tumbang Rungan Village, Palangka Raya, Central Borneo the soil conditions around this location are dominated by clay. Clay soils have an effect on building and road construction, namely experiencing obstacles in their construction. This study Purpose to stabilization the original soil using material additives as cement, husk ash, and fly ash. The results of testing the physical properties of the original soil obtained the value, the water content $(w)=$ $41.37 \%$; density test $(\gamma d)=1.45 \mathrm{~g} / \mathrm{cm}^{3}$; specific gravity $(G s)=2.70 ; L L=46.49 \%$; $P L=30.33 \% ; P I=16.16 \% ; S L=22.97 \%$. According to AAHSTO, the soil is classified as clay soil in group A-7-5. The results of testing the mechanical properties of the original soil for the optimum moisture content $(O M C)=26.30 \%$; density test $(Y d \max )=1.420 \mathrm{~g} / \mathrm{cm}^{3}$; and the CBR value of the original land is $3.97 \%$. With a mixture of cement, husk ash, and fly ash it has an impact on increasing the CBR value. The addition of 5\%, 7.5\%, and $10 \%$ mixed variations resulted in an increase in the CBR value of the plan by $6.80 \% ; 8.00 \%$; and $8.80 \%$. The largest CBR value occurred in the addition of $10 \%$ fly ash, which was $8.80 \%$, an increase of $121.66 \%$ from the CBR value of the original land. From the results of the planned CBR values obtained, the DDT values increased by 5.28,5.58, and 
5.76. The greatest DDT value occurred in the addition of $10 \%$ fly ash, which was 5.76 , an increase of $30.37 \%$ from the original soil DDT value.

Keywords: CBR, Fly Ash, Cement, Husk Ash, Clay Soil, Additives

\section{PENDAHULUAN}

\section{Latar Belakang}

Tanah merupakan dasar dari suatu struktur atau konstruksi perkerasan jalan. Dalam membangun suatu konstruksi jalan, tanah dasar (Subgrade) adalah bagian yang sangat penting. Fungsi dari tanah dasar dalam suatu konstruksi jalan adalah memikul beban lalu lintas yang berada di atas sebuah perkerasan. Berdasarkan observasi lapangan di Kelurahan Tumbang Rungan Palangka Raya, Kalimantan Tengah kondisi tanah di sekitar lokasi tersebut didominasi oleh tanah lempung yang membuat konstruksi pada bangunan dan jalan mengalami kendala dalam pembangunan, menyebabkan jalan di sekitar kelurahan tersebut menjadi retak dan rusak, oleh karena itu perlu dilakukan penelitian untuk menetukan apa jenis dan klasifikasi tanah yang terdapat di Kelurahan tersebut apakah perlu dilakukannya stabilisasi atau tidak. Sampel tanah diambil dari sekitar ruas jalan Kelurahan Tumbang Rungan Palangka Raya dan diambil pada satu titik di daerah tersebut. Salah satu upaya untuk memperbaiki sifat tanah tersebut adalah dengan cara menstabilisasi tanah dengan tujuan menginkatkan daya dukung tanah tersebut yang dapat dilihat dari nilai CBR (California Bearing Ratio). Nilai CBR tersebut akan berbanding lurus dengan daya dukungnya, artinya semakin tinggi nilai CBR, maka semakin tinggi pula daya dukung tanah dasar. Stabilisasi tanah dapat dilakukan dengan cara dipadatkan atau mencampurkan bahan lain (aditif) yang dapat memperbaiki sifat-sifat tanah. Pada penelitian ini ada beberapa zat aditif yang digunakan dalam pencampuran yaitu seperti semen portland, abu sekam, dan fly ash. Penelitian ini diharapkan dapat menstabilkan dan mengurangi sifat buruk dari tanah lempung.

\section{Tujuan Penelitian}

Adapun tujuan dari penelitian ini:

1. Mengetahui sifat-sifat fisik dan mekanik tanah lempung di Kelurahan Tumbang Rungan Palangka Raya, Kalimantan Tengah.

2. Menganalisis peningkatan nilai daya dukung tanah lempung yang telah ditambahkan semen portland, abu sekam, dan fly ash terhadap tanah asli dengan menggunakan, tes CBR.

3. Menganalisis pengaruh variasi kadar campuran pada stabilisasi tanah lempung yang ditambahkan semen portland, abu sekam, dan fly ash.

\section{TINJAUAN PUSTAKA}

\section{Tanah Lempung}

Tanah lempung merupakan agregat partikel-partikel berukuran mikroskopik dan submikroskopik yang berasal dari pembusukan kimiawi unsur-unsur penyusun batuan. Dalam keadaan kering tanah lempung sangatlah keras, dan tak mudah terkelupas hanya dengan jari tangan. sedangkan pada keadaan air yang lebih tinggi, tanah lempung akan bersifat lengket (kohesif) dan sangat lunak (Terzaghi dan Peck, 1987). 


\title{
Semen Portland
}

Fungsi semen adalah mengikat butir-butir agregat hingga membentuk suatu massa padat dan mengisi rongga-rongga udara di antara butir-butir agregat. Semen dikelompokaan ke dalam dua jenis yaitu semen hidrolis dan non-hidrolis. Semen hidrolis adalah suatu bahan pengikat yang mengeras jika bereaksi dengan air serta menghasilkan produk yang tahan air, sedangkan semen non-hidrolis adalah suatu bahan pengikat yang bila dicampur dengan air menghasilkan produk yang dapat mengeras setelah bereaksi dengan karbondioksida, bukan dengan air.

\begin{abstract}
Abu Sekam
Abu sekam padi adalah sisa pembakaran dari sekam padi sehingga sering juga disebut sebagai limbah sisa proses pembakaran. Salah satu fungsi dari abu sekam padi adalah sebagai filler. Fungsi dari filler adalah sebagai bahan pengisi ronggarongga antar agregat (kasar) yang diharapkan dapat meningkatkan kerapatan dan memperkecil permeabilitas dari campuran. Di samping ukurannya yang harus relatif halus, bahan filler harus memiliki sifat-sifat tertentu seperti bersifat sementasi jika terkena air dan memiliki daya rekat yang tinggi dengan agregat lainnya (Mutohar, 2002).
\end{abstract}

\section{Fly Ash}

Fly ash yang disebut juga sebagai abu terbang, adalah limbah hasil pembakaran batu bara pada furnace (tungku pembakaran) pada PLTU yang berbentuk partikel halus dan bersifat pozzolan, karena bahan penyusun utamanya adalah silikon dioksida ( $\mathrm{SiO} 2$ ), alumunium (Al2O3) dan Ferrum oksida (Fe2O3). Oksida-oksida tersebut dapat bereaksi dengan kapur bebas yang dilepaskan semen ketika bereaksi dengan air.

\section{Pemadatan Tanah}

Pemadatan adalah suatu proses memadatnya partikel tanah sehingga terjadi pengurangan volume udara dan volume air dengan memakai cara mekanis. Di lapangan, usaha pemadatan dihubungkan dengan jumlah gilasan dari mesin gilas, atau hal lain yang prinsipnya sama untuk suatu volume tanah tertentu. Di laboratorium, pemadatan didapat dari tumbukan. Selama pemadatan palu dijatuhkan dari ketinggian tertentu beberapa kali pada beberapa lapisan tanah dalam suatu cetakan. Tujuan pemadatan adalah untuk meningkatkan kepadatan, meningkatkan stabilitas, meningkatkan kekuatan tahanan tanah dasar, mengurangi sifat kemudahan ditembus oleh air, mengurangi potensi likuifaksi dan mencegah erosi (Siagian, 2013).

\section{Uji CBR (California Bearing Ratio)}

Metode perencanaan perkerasan jalan yang umum dipakai adalah cara-cara empiris dan yang biasa dikenal adalah cara CBR (California Bearing Ratio). Metode ini dikembangkan oleh California State Highway Departement sebagai cara untuk menilai kekuatan tanah dasar jalan. Istilah CBR menunjukkan suatu perbandingan (ratio) antara beban yang diperlukan untuk menekan piston logam (luas penampang 3 sqinch) ke dalam tanah untuk mencapai penurunan (penetrasi) tertentu dengan beban yang diperlukan pada penekanan piston terhadap material batu pecah di California pada penetrasi yang sama (Canonica, 1991). 
Tabel 1. Klasifikasi Nilai CBR Tanah

\begin{tabular}{ccc}
\hline CBR $(\%)$ & Tingkatan Umum & Kegunaan \\
\hline $0-3$ & Very poor & Subgrade \\
$3-7$ & Poor to fair & Subgrade \\
$7-20$ & Fair & Subbase \\
$20-50$ & Good & Base or subbase \\
$>50$ & Excellent & Base \\
\hline
\end{tabular}

Sumber: Bowles, 1991.

\section{METODE PENELITIAN}

\section{Lokasi Penelitian}

Penelitian ini menggunakan sampel tanah yang berasal dari kawasan Kelurahan Tumbang Rungan Palangka Raya, Kalimantan Tengah. Studi penelitian ini dilakukan di Laboratorium Mekanika Tanah Jurusan/Program Studi Teknik Sipil Fakultas Teknik Universitas Palangka Raya.

\section{Metode Pengambilan Data}

Pada penelitian ini pengambilan sampel tanah lempung didapatkan dari kawasan Kelurahan Tumbang Rungan Palangka Raya, Kalimantan Tengah. Ada dua sampel tanah yang diambil yaitu sampel tanah asli (undisturbed) yaitu tanah yang tidak mengalami perubahan sifat mekaniknya dan sampel tanah terganggu (disturbed) yaitu tanah yang telah terjamah atau sudah tidak alami lagi yang telah terganggu oleh lingkungan luar.

\section{Perencanaan Campuran}

Metode pencampuran tanah asli:

a) Sampel tanah yang telah ditumbuk (butir aslinya tidak pecah) dan lolos saringan No. $4(4,75 \mathrm{~mm})$ lalu dicampur dengan semen dan abu sekam dengan kadar campuran semen 5\% dan abu sekam 5\% dari berat tanah, dan fly ash dengan kadar campuran 0\%, 5\%, 7,5\% 10\% dari berat tanah.

b) Lalu dilakukan pemeraman selama 4 hari untuk pengujian pemadatan dan pengujian CBR.

c) Setelah didapatkan kadar air optimal dari pemadatan lalu dilakukan pengujian CBR.

d) Setelah didapat variasi yang paling optimum, lalu dilakukan analisis data dan pengolahan data. 


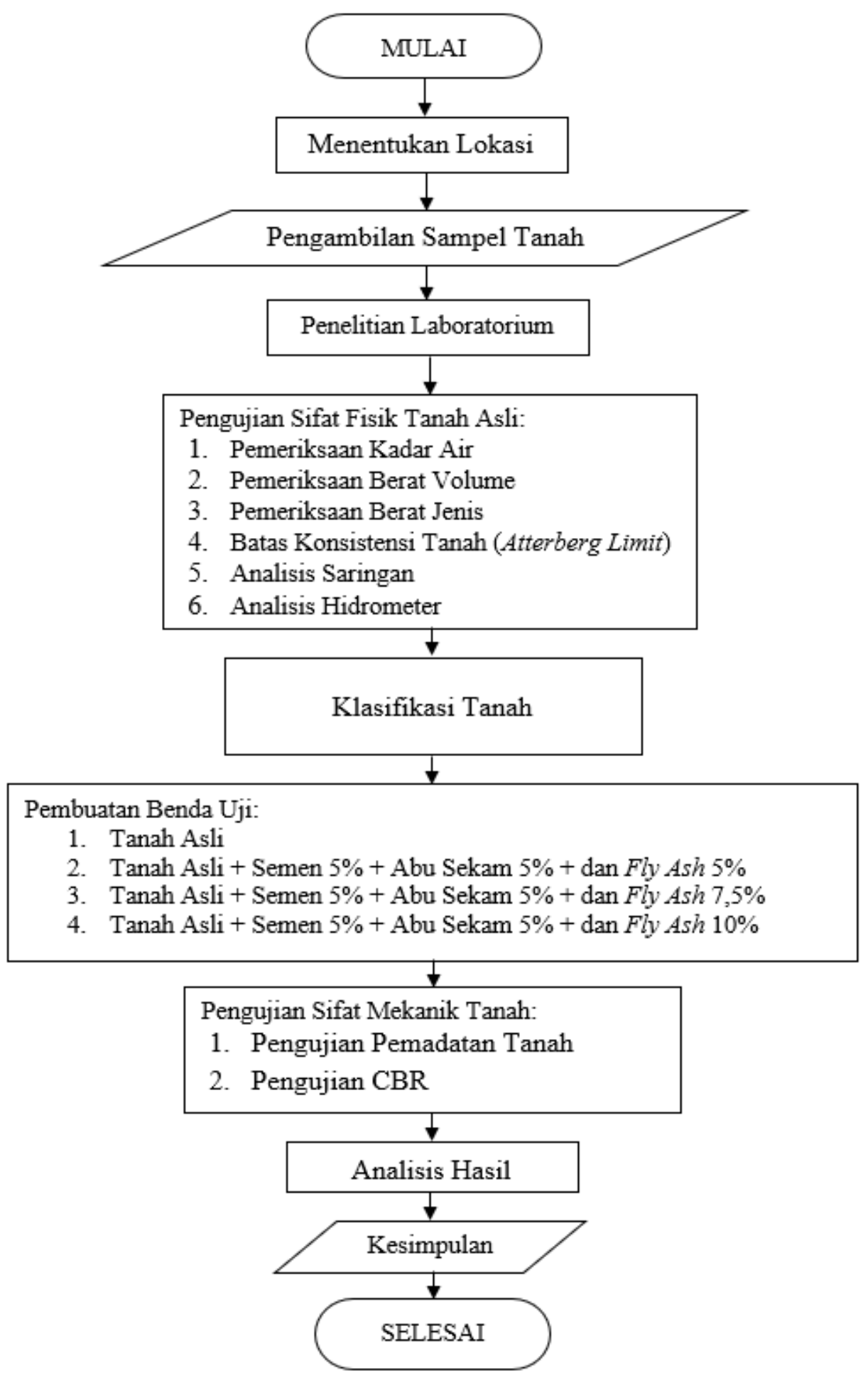

Gambar 1. Bagan Alir Penyusunan Penelitian 


\section{HASIL DAN PEMBAHASAN}

Berdasarkan penelitian yang dilakukan di Laboratorium Mekanika Tanah, Fakultas Teknik Universitas Palangka Raya. Penelitian ini diharapkan dapat memberikan gambaran mengenai karakteristik tanah, yang meliputi sifat fisik dan mekaniknya.

\section{Hasil Pengujian Sifat-Sifat Fisik Tanah}

Tabel 2. Hasil Pemeriksaan Sifat Fisik Tanah

\begin{tabular}{clc}
\hline No. & \multicolumn{1}{c}{ Jenis Pemeriksaan } & $\begin{array}{c}\text { Hasil Pengujian } \\
\text { Rata - rata }\end{array}$ \\
\hline 1. & Kadar Air (Water Content) \% & 41,37 \\
2. & Berat Isi (Density Test) gr/cm $\mathrm{cm}^{3}$ & 1,45 \\
3. & Berat Jenis (Specific Gravity) & 2,70 \\
4. & Batas-Batas Atterberg (\%) & - \\
& a. Batas Cair (Liquid Limit) & 46,49 \\
& b. Batas Plastis (Plastic Limit) & 30,33 \\
& c. Indeks Plastisitas (Plasticity Index) & 16,16 \\
& d. Batas Susut (Shrinkage Limit) & 22,97 \\
5. & Analisis Saringan & - \\
& a. Persentase Berat Tertahan (\%) & 9,65 \\
& b. Persentase Lolos No. 200 (\%) & 50,68 \\
6. & Analisis Hydrometer (\%) & 25,89 \\
\hline
\end{tabular}

Dari sistem klasifikasi tanah menurut AAHSTO tanah tersebut masuk dalam kelompok A-7-5, yaitu tanah jenis berlempung. Kelompok A-7-5 adalah kelompok tanah lempung yang lebih bersifat plastis. Tanah ini mempunyai sifat perubahan volume besar.

\section{Hasil Pengujian Sifat-Sifat Mekanik Tanah Uji Pemadatan}

Pengujian pemadatan tanah dilakukan dengan cara pemadatan metode modified yang menggunakan standar ASTM D 698. Pengujian ini dilakukan untuk mendapatkan kadar air optimum dan berat volume kering tanah maksimum yang digunakan sebagai kadar air pada pengujian CBR.

Tabel 3. Rekapitulasi Hasil Pengujian Pemadatan Laboratorium

\begin{tabular}{cccc}
\hline Variasi Campuran & $\begin{array}{c}\text { Waktu } \\
\text { Pemeraman }\end{array}$ & $\begin{array}{c}\text { Kadar } \\
\text { Air } \\
\text { Optimum } \\
(\%)\end{array}$ & $\begin{array}{c}\text { Kepadatan } \\
\text { Maksimum } \\
\left(\mathrm{g} / \mathrm{cm}^{3}\right)\end{array}$ \\
\hline Tanah Asli & 0 Hari & 26,30 & 1,420 \\
T. Asli + S.P 5\% + A.S 5\% + Fly Ash 5\% & 4 Hari & 20,71 & 1,554 \\
T. Asli + S.P 5\% + A.S 5\% + Fly Ash 7,5\% & 4 Hari & 21,73 & 1,575 \\
T. Asli + S.P 5\% + A.S 5\% + Fly Ash 10\% & 4 Hari & 22,70 & 1,600 \\
\hline
\end{tabular}


Pada tabel di atas menunjukan bahwa kadar air optimum pada tanah asli adalah sebesar $26,30 \%$ dengan kepadatan maksimum $1,420 \mathrm{~g} / \mathrm{cm}^{3}$, yang berarti kadar air pada tanah asli adalah yang paling terbesar sedangkan pada kepadatan maksimum yang paling terendah. Sedangkan pada setiap penambahan variasi kadar campuran semen, abu sekam, dan fly ash terlihat berdampak baik pada nilai kepadatan maksimum pada setiap penambahan kadar variasinya, yang membuat kepadatan maksimum tanah meningkat seiring meningkatnya kadar air optimum juga. Peningkatan maksimal terjadi dipenambahan Fly Ash 10\%, dengan kepadatan maksimum mencapai $1,600 \mathrm{~g} / \mathrm{cm}^{3}$ dan kadar air optimum sebesar $22,70 \%$.

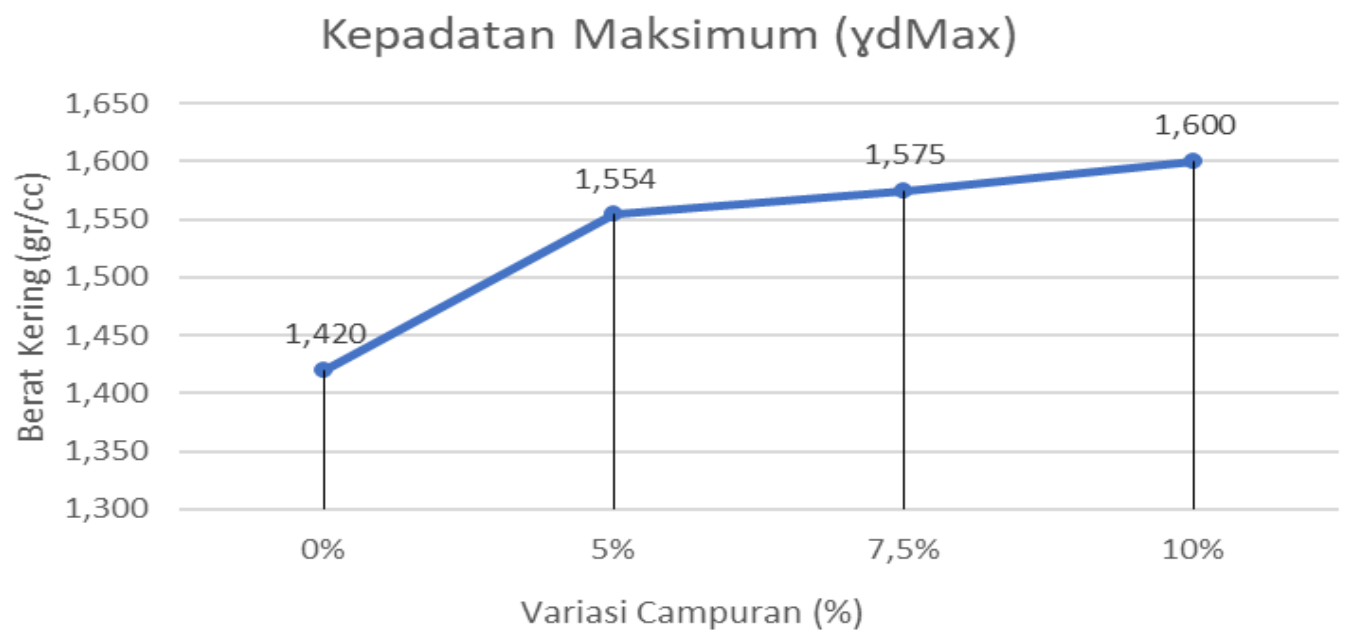

\section{Gambar 2. Grafik Hasil Pengujian Pemadatan Laboratorium}

Dapat dilihat pada gambar grafik di atas bahwa kepadatan maksimum tanah asli adalah sebesar $1,420 \mathrm{~g} / \mathrm{cm}^{3}$. Setelah dilakukan penambahan variasi kadar campuran terjadi kenaikan nilai dari kepadatan maksimum tanah asli. Pada penambahan fly ash 5\% kepadatan maksimum tanah naik sebesar $1,554 \mathrm{~g} / \mathrm{cm}^{3}$ meningkat sebesar 9,44\% dari berat maksimum tanah asli, pada penambahan fly ash 7,5\% kepadatan maksimum tanah naik sebesar $1,575 \mathrm{~g} / \mathrm{cm}^{3}$ meningkat sebesar $10,92 \%$ dari berat maksimum tanah asli, pada penambahan fly ash $10 \%$ kepadatan maksimum tanah naik sebesar $1,600 \mathrm{~g} / \mathrm{cm}^{3}$ meningkat sebesar $12,68 \%$ dari berat maksimum tanah asli. Dapat disimpulkan bahwa kenaikan kepadatan maksimum terbesar terjadi pada penambahan fly ash $10 \%$.

\section{Uji CBR}

Pengujian ini dimaksudkan untuk menentukan nilai CBR dengan mengetahui kuat hambatan campuran tanah dengan semen, abu sekam, dan fly ash terhadap penetrasi kadar air optimum dengan waktu pemeraman 4 hari dengan variasi campuran $0 \%$, $5 \%, 7,5 \%$ dan $10 \%$. 
Tabel 4. Rekapitulasi Hasil Pengujian CBR Laboratorium

\begin{tabular}{cccc}
\hline Variasi Campuran & $\begin{array}{c}\text { Waktu } \\
\text { Pemeraman }\end{array}$ & $\begin{array}{c}\text { Kepadatan } \\
\text { Maksimum } \\
\left(\mathrm{g} / \mathrm{cm}^{3}\right)\end{array}$ & $\begin{array}{c}\text { Nilai } \\
\text { CBR } \\
\text { Tanah Asli } \\
(\%)\end{array}$ \\
\hline T. Asli + S.P 5\% + A.S 5\% + Fly Ash 5\% & 4 Hari & 1,420 & $3,97 \%$ \\
T. Asli + S.P 5\% + A.S 5\% + Fly Ash 7,5\% & 4 Hari & 1,554 & $6,80 \%$ \\
T. Asli + S.P 5\% + A.S 5\% + Fly Ash 10\% & 4 Hari & 1,575 & $8,00 \%$ \\
\hline
\end{tabular}

Pada tabel di atas menunjukan bahwa nilai CBR pada tanah asli cukup rendah yaitu $3,97 \%$. Sedangkan pada setiap penambahan variasi kadar campuran semen, abu sekam, dan fly ash berdampak sangat signifikan terhadap naiknya nilai CBR pada setiap penambahan kadar variasinya. Peningkatan maksimal terjadi dipenambahan Fly Ash 10\%, dengan nilai CBR maksimum mencapai 8,80\%.

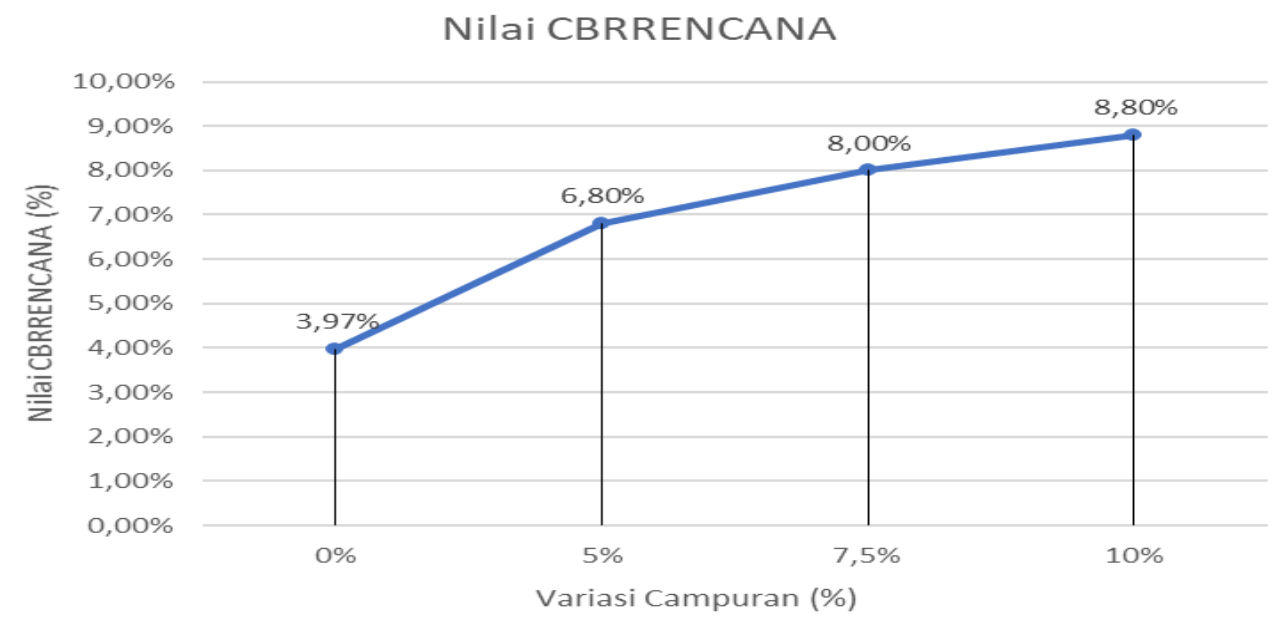

Gambar 3. Grafik Hasil Pengujian CBR Laboratorium

Dapat dilihat pada gambar grafik di atas dapat disimpulkan bahwa nilai CBR tanah asli cukup rendah yaitu $3,97 \%$. Sedangkan penambahan semen, abu sekam, dan fly ash dengan waktu pemeraman 4 hari, dapat meningkatkan nilai CBR bahkan di setiap penambahan campurannya. Pada campuran pertama nilai CBR naik sebesar $6,80 \%$ meningkat sebesar $71,29 \%$ dari tanah asli, pada campuran kedua nilai CBR naik sebesar $8,00 \%$ meningkat sebesar $101,51 \%$ dari tanah asli, dan campuran ketiga nilai CBR naik sebesar 8,80\% meningkat sebesar 121,66\% dari tanah asli. 


\section{Hubungan Daya Dukung Tanah dengan CBR Rencana}

Daya dukung tanah dasar (DDT) merupakan salah satu parameter yang digunakan dalam nonogram penetapan indeks tebal perkerasan (ITP). Nilai daya dukung tanah dasar didapat dari hari grafik kolerasi CBR tanah dasar terhadap DDT, secara analitis nilai DDT dengan menggunakan persamaan berikut (Sukirman,1999).

DDT $=4,3 \log \mathrm{CBR}+1,7$

Keterangan:

DDT: daya dukung tanah dasar

CBR: nilai CBR tanah dasar

Dengan Maka didapat nilai DDT sebagai berikut :

$\operatorname{DDT}=4,3 \times \log (8,80)+1,7=5,76$

Tabel 5. Rekapitulasi Hasil Hubungan Daya Dukung Tanah Dasar dengan CBR Rencana

\begin{tabular}{cccc}
\hline Variasi Campuran & $\begin{array}{c}\text { Waktu } \\
\text { Pemeraman }\end{array}$ & $\begin{array}{c}\text { Nilai } \\
\text { CBR } \\
\text { RENCANA } \\
(\%)\end{array}$ & $\begin{array}{c}\text { Nilai Daya } \\
\text { Dukung } \\
\text { Tanah Dasar }\end{array}$ \\
\hline Tanah Asli & 0 Hari & $3,97 \%$ & 4,28 \\
T. Asli + S.P 5\% + A.S 5\% + Fly Ash 5\% & 4 Hari & $6,80 \%$ & 5,28 \\
T. Asli + S.P 5\% + A.S 5\% + Fly Ash 7,5\% & 4 Hari & $8,00 \%$ & 5,58 \\
T. Asli + S.P 5\% + A.S 5\% + Fly Ash 10\% & 4 Hari & $8,80 \%$ & 5,76 \\
\hline
\end{tabular}

Dari tabel di atas dapat dilihat bahwa DDT tanah asli adalah sebesar 4,28. Dengan penambahan semen, abu sekam, dan fly ash nilai DDT meningkat di setiap penambahan campurannya, pada campuran pertama nilai DDT meningkat sebesar 5,28 meningkat sebesar $23,36 \%$ dari nilai DDT tanah asli, pada campuran kedua nilai DDT meningkat sebesar 5,58 meningkat sebesar 30,37\% dari nilai DDT tanah asli, dan pada campuran ketiga nilai DDT meningkat sebesar 5,76 meningkat sebesar 34,58\% dari nilai DDT tanah asli. Peningkatan nilai DDT terbesar terjadi pada campuran ketiga, nilai DDT naik sebesar 5,76 dari DDT tanah asli sebesar 4,28 .

\section{PENUTUP}

\section{Kesimpulan}

Berdasarkan penelitian yang telah dilakukan, maka dapat diambil kesimpulan sebagai berikut:

1. Hasil pengujian sifat-sifat fisik tanah asli didapat nilai, kadar air $(w)=41,37 \%$; berat isi kering $\left(\gamma_{\mathrm{d}}\right)=1,45 \mathrm{~g} / \mathrm{cm}^{3}$; berat jenis $(G s)=2,70 ; \mathrm{LL}=46,49 \%$; PL $=$ 30,33\%; PI = 16,16\%; $\mathrm{SL}=22,97 \%$; Analisis saringan persentase lolos saringan No. $200=50,68 \%$. Dari sistem klasifikasi tanah menurut AAHSTO tanah tersebut diklasifikasikan sebagai tanah berlempung dalam kelompok A-7-5. 
2. Hasil uji sifat mekanik tanah untuk pemadatan laboratorium untuk sampel tanah asli, nilai kadar air optimum $(O M C)=26,30 \%$; berat isi kering $\left(\gamma_{\mathrm{d} \text { max }}\right)=1,420$ $\mathrm{g} / \mathrm{cm}^{3}$; dan nilai CBR tanah asli adalah 3,97\%.

3. Campuran semen, abu sekam, dan fly ash yang dicampurkan dengan tanah asli berdampak pada meningkatnya nilai CBR, dengan variasi campuran yang berbeda-beda dan waktu pemeraman selama 4 hari. Setelah ditambah dengan variasi campuran $5 \%, 7,5 \%$, dan $10 \%$ didapat nilai CBR RENCANA meningkat sebesar $6,80 \% ; 8,00 \%$; dan 8,80\%. Nilai CBR terbesar terjadi dipenambahan fly ash $10 \%$ yaitu sebesar $8,80 \%$ meningkat $121,66 \%$ dari nilai CBR tanah asli.

4. Dari hasil nilai CBR RENCANA yang didapat, dapat dihitung nilai DDT dari hubungan antara nilai daya dukung tanah dasar dengan CBR RENCANA. Nilai DDT tanah asli adalah sebesar 4,28 dengan penambahan semen, abu sekam, dan fly ash nilai DDT meningkat sebesar 5,28, 5,58, dan 5,76. Nilai DDT terbesar terjadi dipenambahan fly ash 10\% yaitu sebesar 5,76 meningkat 30,37\% dari nilai DDT tanah asli.

\section{Saran}

Berdasarkan hasil dari penelitian dan analisis data yang dilakukan, maka disarankan hal-hal sebagai berikut:

1. Setiap tanah dasar pada tiap daerah memiliki sifat fisik yang berbeda, oleh karena itu perlu dilakukan pengujian sifat fisik tanah.

2. Untuk melihat kenaikan atau penurunan CBR tanah, sebaiknya dilakukan perbandingan umur pemeraman dan dilakukan perendaman.

3. Pemeriksaan pemadatan laboratorium dan pemeriksaan CBR laboratorium dapat menggunakan cara modified agar lebih bervariasi.

4. Untuk melihat kenaikan atau penurunan CBR tanah, sebaiknya dilakukan perbandingan variasi campuran dengan kadar lebih tinggi.

5. Pengawasan yang maksimal perlu dilakukan pada pelaksanaan pembuatan sampel di laboratorium dan juga perlu diperhatikan kondisi peralatan yang digunakan pada saat penelitian sehingga diperoleh data yang akurat.

\section{DAFTAR PUSTAKA}

1. Bowles, Joseph E. Johan . Helnim. 1991. Sifat-sifat Fisis Geoteknis Tanah (Mekanika Tanah). PT. Erlangga. Jakarta, 151 Halaman.

2. Das, B. M. 1998. Mekanika Tanah (Prinsip-prinsip Rekayasa Geoteknik), Erlangga : Jakarta.

3. Hardiyatmo, Hary Christady. 1992. Mekanika Tanah 1. PT. Gramedia Pustaka Utama . Jakarta.

4. Hardiyatmo, Hary Christady. 2010. Stabilisasi Tanah Untuk Perkerasan Jalan. Gadjah Mada University Press. Yogyakarta.

5. Hardiyatmo, Hary Christady. 2012. Mekanika Tanah 1, Edisi Keenam. Gajah Mada University Press. Yogyakarta. 